Artigo

\title{
Classicação Sinótica de Frentes Frias Associadas a Chuvas Extremas no Leste de Santa Catarina (SC)
}

\author{
Gustavo C.J. Escobar ${ }^{1}$, Marcelo E. Seluchi², Kelen Andrade ${ }^{3}$ \\ ${ }^{1}$ Centro de Previsão de Tempo e Estudos Clmáticos, Instituto Nacional de Pesquisas Espaciais, \\ Cachoeira Paulista, SP, Brasil. \\ ${ }^{2}$ Centro Nacional de Monitoramento e Alerta de Desastres Naturais, \\ Cachoeria Paulista, SP, Brasil. \\ ${ }^{3}$ Centro Nacional de Monitoramento e Alerta de Desastres Naturais, \\ São José dos Campos, SP, Brasil.
}

Recebido: 9/12/2015 - Aceito: 14/2/2016

\begin{abstract}
Resumo
O trabalho apresenta uma classificação sinótica de frentes frias sobre o leste do Estado de Santa Catarina (SC), com o propósito de identificar os principais padrões sinóticos associados com chuvas extremas na região do Vale do Itajaí. A metodologia utilizada foi a técnica de Análise de Componentes Principais aplicada à série de reanálises do Climate Forecast System Reanalysis (CFSR) (NCEP) para o período 1979-2010. Previamente, realiza-se uma climatologia de frentes frias sobre o leste de SC, cujos resultados mostram uma maior frequência de frentes frias associadas a chuvas extremas no Vale do Itajaí durante a primavera. Os resultados fornecem cinco padrões sinóticos principais que representam $83,4 \%$ dos casos de frentes frias com chuvas extremas no Vale do Itajaí. O padrão sinótico mais frequente mostra um intenso fluxo de quadrante sudeste sobre a região de estudo, determinado pela presença de um forte anticiclone pós-frontal observado sobre o sul da Província de Buenos Aires, cuja frente fria associada encontra-se no extremo nordeste catarinense. Por último, há dois padrões sinóticos típicos de verão relacionados com chuvas extremas no Vale do Itajaí; um relacionado com episódios de Zona de Convergência do Atlântico Sul (ZCAS) e outro associado com a Baixa do Chaco (BCH).
\end{abstract}

Palavras chave: classificação de frentes, componentes principais, chuvas extremas.

\section{Synoptic Classification of Cold Fronts Associated with Extremes Rainfall over the East of Santa Catarina State}

\begin{abstract}
This paper presents a synoptic classification of cold fronts over the east of Santa Catarina (SC) state, in order to identify the main synoptic patterns associated with extreme rainfall over Itajaí Valley region. To this purpose, the Principal Component Analysis technique was applied to the Climate Forecast System Reanalysis (CFSR) (NCEP) for the period 1979-2010. Previously, it was carried out a climatology of cold fronts over the east of SC, whose main results show a higher frequency of fronts associated with extreme rainfall over Itajaí Valley during spring. The results provide five main synoptic patterns that are representative of about $83.4 \%$ of all the cases of cold fronts with extreme rainfall over the Itajaí Valley region. The most frequent synoptic pattern shows an intense southeast quadrant flow over the studied area, determined by the presence of a strong post-frontal anticyclone observed over southern Buenos Aires state, whose cold front associated is in the extreme northeastern part of the SC state. Finally, there are two summer typical synoptic patterns related to extreme rainfall in the Itajaí Valley region; one related to the South Atlantic Convergence Zone (SACZ) episodes and another associated with the Chaco Low (CHL).
\end{abstract}

Keywords: fronts classification, principal components, extremes rainfall.

Autor de correspondência: Gustavo C.J. Escobar, gustavo.escobar@inpe.br. 


\section{Introdução}

O Vale do Itajaí é uma das mesoregiões do Estado de Santa Catarina (SC) mais vulneráveis aos desastres naturais associados a eventos meteorológicos extremos. As inundações e os deslizamentos de terra são os desastres que causam o maior número de vítimas e afetados, sendo que a maioria deles são decorrentes da atuação de sistemas frontais (Marcelino e Goerl, 2004; Herrmann et al. (2004)).

A geografia irregular que apresenta a região do Vale do Itajaí, caracteriza-se pela presença de serras localizadas ao sul e a oeste do vale, que oscilam em média entre $1000 \mathrm{~m}$ e $1500 \mathrm{~m}$ de altitude, assim como de pequenas elevações junto ao Oceano Atlântico. Devido às características topográficas os ventos de quadrante leste, de origem marítima, facilitam a convergência da umidade no interior do vale e, portanto, a ocorrência de chuvas. Segundo Severo et al. (1996), através da análise de 21 casos, essas chuvas são provocadas principalmente pela passagem de sistemas frontais.

As frentes frias são os sistemas meteorológicos mais comuns que modificam as condições de tempo sobre o centro-sul do continente sul-americano. Segundo a climatologia elaborada por Cavalcanti e Kousky (2009), que analisaram a distribuição espacial da atividade frontal sobre a América do Sul, existem duas regiões preferenciais com maior frequência de passagens frontais: A primeira se localiza imediatamente a leste da Cordilheira dos Andes e a segunda sobre o litoral das regiões Sul e Sudeste, provavelmente relacionada à presença da Serra do Mar. Esse resultado coloca à porção leste de $\mathrm{SC}$ como uma das regiões com maior frequência de passagens de sistemas frontais no Brasil.

As frentes frias que atingem a Região Sul do Brasil, incluindo o Estado de SC, apresentam diferentes trajetórias que variam ao longo do ano. A maioria delas vem do sul do continente atravessando o Chile, a Argentina, o Uruguai e o Paraguai (Foss et al. (2013)). As frentes frias atingem a Região Sul do Brasil ao longo do ano, porém com maior frequência entre os meses de maio e setembro. Entre os meses de outubro e abril, as frentes frias são menos frequentes nessa região, já que apresentam um deslocamento mais zonal e marítimo (Olivera, 1986; Lemos e Calbete, 1996; Justi da Silva e Silva Dias, 2002; Andrade, 2005; Cavalcanti e Kouski, 2009).

Rodrigues et al. (2004) elaboraram uma climatologia de frentes frias para o litoral do Estado de SC, baseada em 10 anos (1990-1999) de dados de reanálises do NCEPNCAR. Os resultados mostraram que as frentes frias se deslocam em média de sudoeste para nordeste ao longo do litoral sul e sudeste de SC, com uma frequência mensal de 3-4 frentes/mês. Os autores também verificaram que a atuação das frentes frias no litoral do Estado ocorre em todas as épocas do ano, com um ligeiro aumento durante a primavera.
Em função da frequente atividade frontal e das características geográficas da região, são vários os episódios de chuva intensa registrados no Vale do Itajaí. Entre eles pode se citar o ocorrido entre os dias 21 e 23 de setembro de 2013 , onde as chuvas superiores em alguns casos aos $300 \mathrm{~mm}$ afetaram mais de 24 mil pessoas em 82 municípios catarinenses. Nessa oportunidade, o Vale do Itajaí foi uma das regiões mais afetadas por enchentes e deslizamentos de terra.

A maioria dos trabalhos de frentes frias associadas com chuvas extremas no leste do Estado catarinense são baseados em análises de casos particulares. Existem também estudos estatísticos (Rodrigues et al., 2004) sobre a atuação média dos sistemas frontais sobre o leste catarinense, mas que não incluem a análise da precipitação associada. Não existem, contudo, até o presente estudos climatológicos que caracterizem as frentes frias com potencial para causar desastres hidro-meteorológicos na região litorânea de Santa Catarina. Assim, este artigo tem como objetivo principal elaborar uma classificação sinótica de frentes frias com potencial para provocar chuvas extremas na região do Vale do Itajaí. Em particular, o trabalho identifica os principais modos de variabilidade da circulação em superfície relacionados com episódios de chuva extrema na área de estudo e os compara com os obtidos para a totalidade das frentes frias que atuam na região. Esses resultados permitirão identificar padrões de circulação em superfície associados a frentes frias com potencial para causar desastres naturais no Vale do Itajaí, melhorando desta maneira a previsibilidade numa das regiões mais vulneráveis do país.

Na seção 2 são apresentados os dados e a metodologia utilizada e a seção 3 mostra os resultados da classificação sinótica de frentes frias no leste do Estado de SC. A seção 4 apresenta um resumo dos principais resultados obtidos neste estudo.

\section{Material e Métodos}

\subsection{Dados}

A seleção dos sistemas frontais e a elaboração da classificação sinótica, foram realizadas utilizando os dados diários de pressão ao nível médio do mar, temperatura e vento em $925 \mathrm{hPa}$ provenientes do Climate Forecast System Reanalysis (CFSR) (Saha et al. (2010)) do National Center for Environmental Prediction (NCEP) com resolução espacial de $0,5^{\circ} \mathrm{C}$, no período de 1979 a 2010.

Para identificar os sistemas frontais associados a eventos extremos de chuva, foram utilizados dados de precipitação no período 1998-2010, obtidos através do produto MERGE (Rozante et al. (2010)), que resulta da combinação de dados observados e estimativas de precipitação derivadas do satélite Tropical Rainfall Measuring Mission (TRMM). 


\subsection{Metodologia}

\subsubsection{Critério de identificação de frentes frias}

Para a identificação dos sistemas frontais foi utilizado o seguinte critério objetivo para a área utilizada: aumento da pressão ao nível médio do mar maior que $2 \mathrm{hPa}$; queda da temperatura maior que $2{ }^{\circ} \mathrm{C}$ e mudança na direção do vento de quadrante norte para quadrante sul em $925 \mathrm{hPa}$. Essas mudanças são médias na área e devem ser observadas simultaneamente entre o dia e o próximo consecutivo. Um critério semelhante foi utilizado por Andrade (2005) em análises climatológicas. Os limiares de $2 \mathrm{hPa}$ e $2{ }^{\circ} \mathrm{C}$ foram encontrados a partir da média mensal de queda de temperatura e aumento da pressão na área de estudo.

Em primeiro lugar, foi feita uma climatologia de frentes frias associadas com eventos extremos de chuva numa área restrita correspondente ao nordeste de SC, incluindo a área vulnerável do Vale do Itajaí $\left(27,5^{\circ}-26^{\circ} \mathrm{S}\right.$, $49,5^{\circ}-48,5^{\circ} \mathrm{O}$ ) (Fig. 1, caixa pequena). Uma vez identificadas as frentes frias nesta pequena região, foram selecionadas apenas os sistemas frontais associados com chuva extrema. Para tal fim, utilizou-se a metodologia proposta em May (2004) e também utilizada por Teixeira e Satyamurty (2007), que leva em consideração o cálculo dos quantis da chuva diária. Assim, na região escolhida foram considerados os valores de chuva superiores ao percentil 95 (o 5\% dos casos mais intensos do total de eventos), que corresponderam a acumulados superiores a $20 \mathrm{~mm} /$ dia.

Para finalizar, foi elaborada uma climatologia de frentes frias numa área maior, compreendida pelo leste de

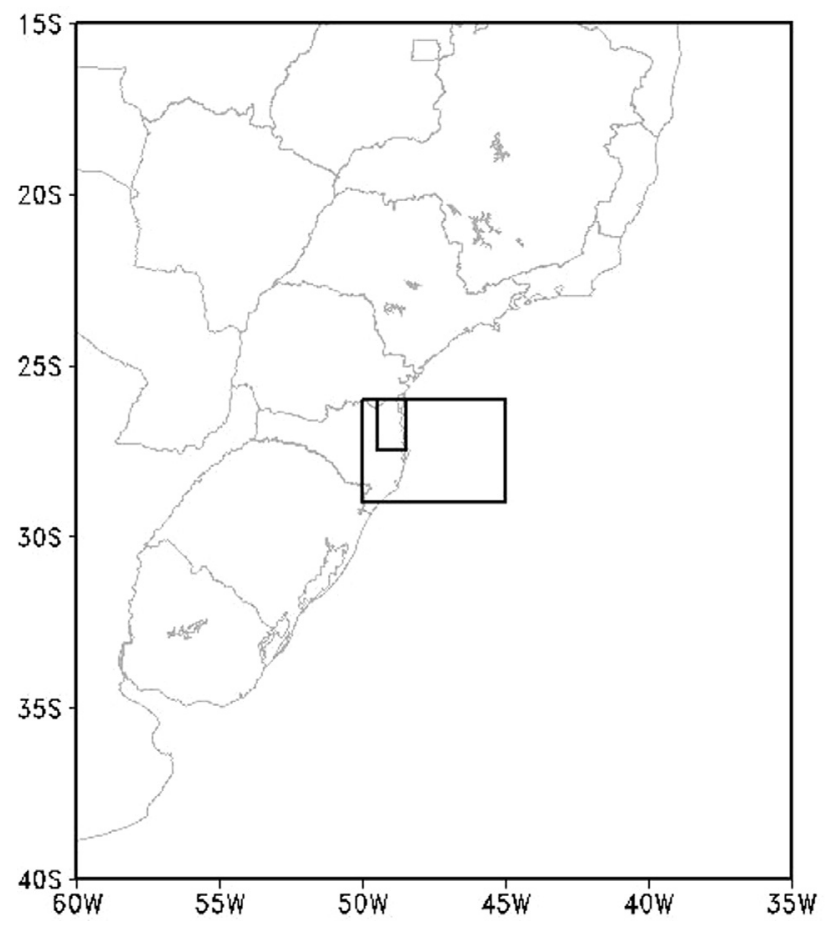

Figura 1 - Área selecionadas para estudo. Caixa grande: leste de SC e oceano adjante. Caixa pequena: Vale do Itajaí
SC e oceano adjacente $\left(29^{\circ}-26^{\circ} \mathrm{S}, 50^{\circ}-45^{\circ} \mathrm{O}\right)$ (Fig. 1, caixa grande).

\subsubsection{Análise de Componentes Principais (ACP)}

Para determinar os principais padrões de circulação em superfície associados às frentes frias com precipitação superior a $20 \mathrm{~mm} /$ dia no Vale do Itajaí (SC) e à totalidade das frentes frias observadas no leste de SC e oceano adjacente, foi realizada uma classificação sinótica dos campos de pressão ao nível do mar. Para isso, foi utilizada a metodologia de Análise de Componentes Principais (ACP) com uma matriz de correlação em Modo - T (Green, 1978; Richman, 1986; Compagnucci e Salles, 1997; Escobar, 1999; Escobar, 2014). Neste caso, a variável estatística analisada corresponde ao campo espacial da variável meteorológica em questão. Desta maneira, identificam-se subgrupos ou tipos de campos com a mesma estrutura espacial. Os dados são dispostos em formato de matriz onde as colunas são determinadas pelos campos espaciais correspondentes a tempos consecutivos. As filas desta matriz de entrada são determinadas pelos pontos de grade. Isto significa que cada coluna representa um campo de pressão atmosférica ao nível do mar.

Após a aplicação do ACP foi feita a rotação Varimax, retendo as componentes principais $(\mathrm{CP})$ significativas para as duas amostras utilizadas. A rotação das componentes principais tem como principal objetivo redistribuir a variância total dos dados utilizados com o intuito de facilitar o significado físico das componentes obtidas (Richman, 1986). Para a determinação do número de componentes rotacionadas utilizou-se a regra do autovalor 1.0 (Richman et al. (1992)).

Para a determinação das situações meteorológicas reais altamente correlacionadas com as $\mathrm{CP}$ foram utilizadas as séries temporais de factor loadings (componentes de peso) que representam as correlações entre cada variável (situação meteorológica real) e cada componente principal (Richman, 1986). A análise da série de factor loadings permite determinar a representatividade das componentes principais como situações sinóticas reais, onde os valores próximos a 1 representam situações meteorológicas similares às componentes principais obtidas (Harman, 1976; Cattel, 1978).

A classificação sinótica permite identificar os principais padrões de circulação em superfície associados a atuação de frentes frias que provocam precipitação superior a $20 \mathrm{~mm} /$ dia na região do Vale do Itajaí e compará-los com os correspondentes à totalidade das frentes frias selecionadas no leste de SC e no oceano adjacente. Por outro lado, o cálculo da variância explicada através das séries temporais de factor loadings (Richman, 1986), permite também determinar as variações sazonais dos padrões de circulação predominantes. Assim, foi determinada para cada CP a variância explicada durante o inverno (maio-setembro) e o verão 
(outubro-abril) a fim de determinar os padrões de circulação dominantes nessas duas épocas do ano.

\section{Resultados e Discussão}

\subsection{Cimatologia de frentes frias}

Nos 13 anos analisados de casos de frentes frias associadas com acumulados diários de chuva superiores aos $20 \mathrm{~mm}$ na região do Vale do Itajaí (SC) (Fig. 1, caixa pequena), foram identificados 80 sistemas frontais. A distribuição anual do número total de frentes frias com esta característica mostra (Fig. 2) dois máximos principais semelhantes; um em janeiro e o outro em setembro. A maior concentração de frentes frias com chuvas diárias acima de $20 \mathrm{~mm}$ é observada entre os meses de julho e novembro e a menor durante os meses de maio e junho. A maior frequência observada na primavera está relacionada, muito provavelmente, ao aumento do conteúdo de umidade que, combinado com a atividade baroclínica, potencializa o aumento na intensidade das chuvas. Durante o mês de junho, mesmo tendo uma importante frequência de passagens frontais, o menor conteúdo de umidade inibe a formação de chuvas volumosas. Por outro lado, o máximo observado em janeiro apresenta relação direta com a maior umidade e instabilidade atmosférica observadas nesta época. O critério de seleção, que utiliza limiares relativamente baixos para a definição das frentes frias, permite que sistemas fracos sejam incorporados à amostra. Alguns desses sistemas, contudo, são capazes de provocar acumulados pluviométricos consideráveis em condições termodinâmicas favoráveis.

Nos 32 anos analisados de casos de frentes frias na área compreendida pelo leste de $\mathrm{SC}$ e oceano adjacente (Fig. 1, caixa grande), foram identificados através do cri- tério objetivo 1028 frentes frias, totalizando uma média mensal de 2,6 sistemas frontais.

A variação ao longo do ano permite identificar, através da Fig. 3, uma maior ocorrência de frentes frias no final do inverno com um máximo absoluto durante o mês de agosto (4,1 frentes/mês). A menor frequência de frentes é observada durante o verão, com um mínimo absoluto no mês de dezembro (1,2 frentes/mês). Também é possível observar um máximo relativo durante o mês de abril $(2,7)$. O máximo do inverno e o mínimo do verão estão relacionados com o posicionamento médio do Jato Polar (JP) ao longo do ano (Escobar, 2009), sendo que durante o inverno o JP fica posicionado mais ao norte e no verão mais ao sul. Estes resultados são semelhantes aos obtidos por Rodrigues et al. (2004), com a diferença em que estes autores obtiveram o máximo absoluto de frentes frias durante a primavera.

Em consequência, pode se estabelecer que as frentes frias associadas a chuvas extremas apresentam uma distribuição anual diferente do total de frentes frias. Enquanto estas últimas são mais frequentes durante o inverno, acompanhando a evolução anual do JP e da baroclinia, as frentes frias que causam chuvas extremas ocorrem com maior frequência na primavera e no mês de janeiro, aliadas a condições termodinâmicas mais favoráveis.

\subsection{Classificação sinótica}

\subsubsection{Frentes frias associadas a chuvas extremas no Vale do Itajaí}

A climatologia sinótica associada a frentes frias relacionadas com precipitação acima de $20 \mathrm{~mm} /$ dia na área do Vale do Itajaí permitiu identificar oito CP (Tabela 1) que explicaram 91,3\% da variância total dos dados, sendo que

\section{Média mensal de frentes frias que provocam chuva acima de $20 \mathrm{~mm}$ no Vale do Itajaí (SC)}

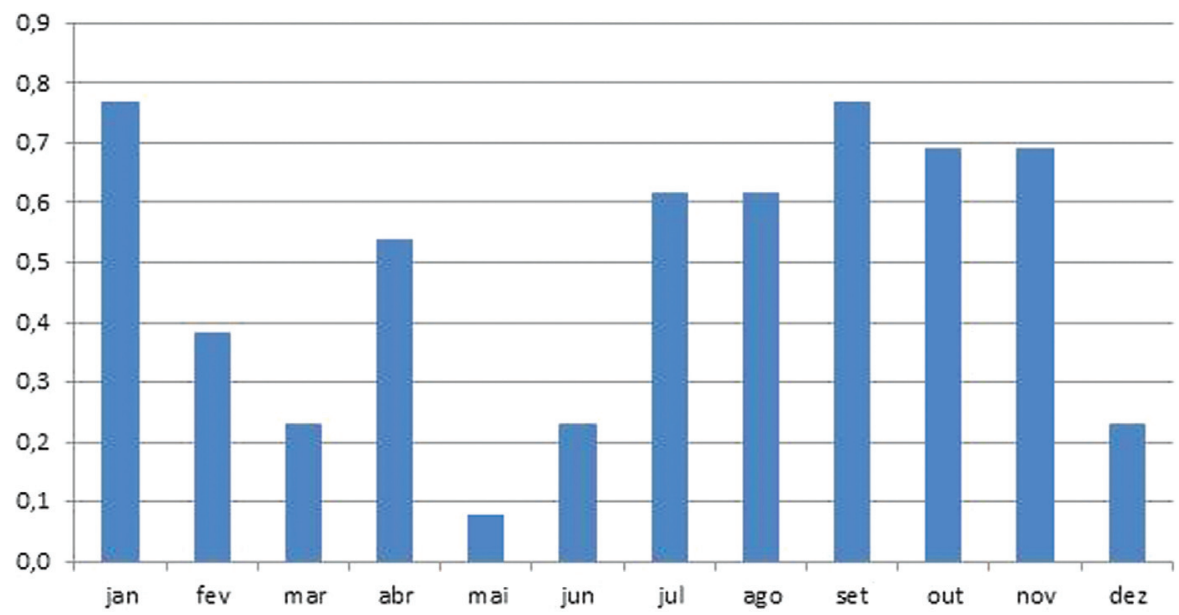

Figura 2 - Distribuição mensal de frequência de frentes frias com chuva acima de 20 mm/dia sobre a região do Vale do Itajaí (SC), para o período 1998 2010 . 
Média mensal de frentes frias no leste de SC

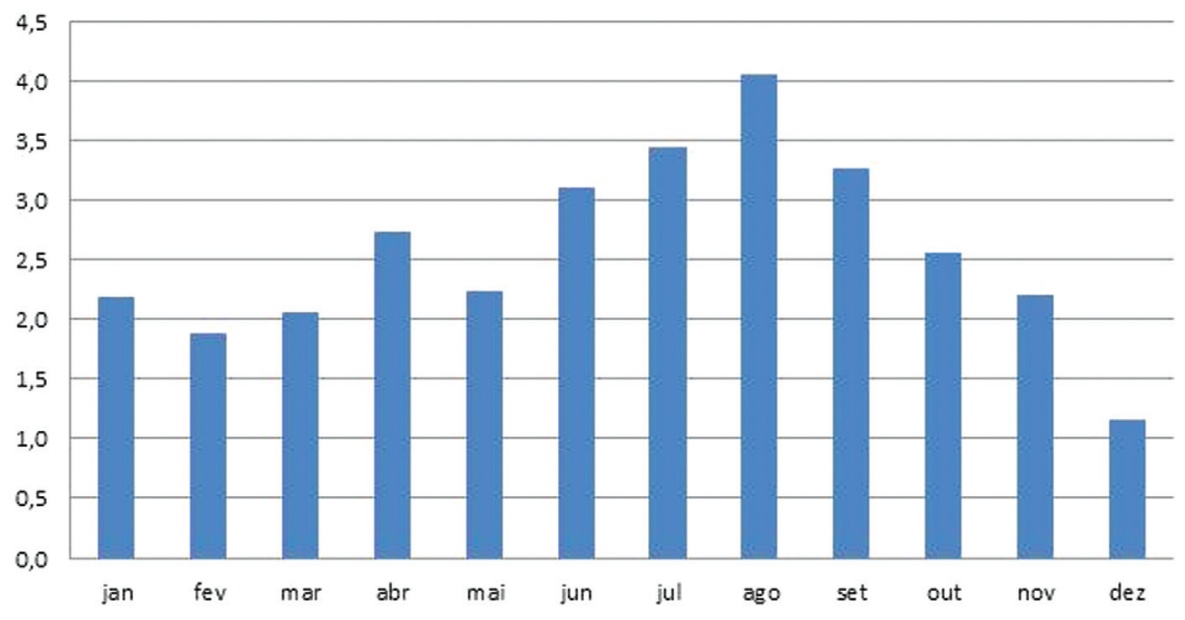

Figura 3 - Distribuição mensal de frequência de frentes frias sobre o leste de SC para o período 1979 - 2010.

Tabela 1 - Porcentagens da variância explicada e da variância acumulada pelas oito primeiras $\mathrm{CP}$, associadas a frentes frias com precipitação acima de $20 \mathrm{~mm}$ na região do Vale do Itajaí.

\begin{tabular}{lcc}
\hline CPs & VAR. (\%) & CUM. VAR (\%) \\
\hline 1 & 26,4 & 26,4 \\
2 & 20,4 & 46,8 \\
3 & 17,8 & 64,6 \\
4 & 10,7 & 75,3 \\
5 & 8,1 & 83,4 \\
6 & 4,0 & 87,4 \\
7 & 2,0 & 89,4 \\
8 & 1,9 & 91,3 \\
\hline
\end{tabular}

as cinco primeiras CP representaram $83,4 \%$ da variância total.

As primeiras cinco séries de componentes de peso (ou factor loadings) (Figs. não mostradas) apresentaram valores maiores que 0,7 . Isto significa que os padrões teóricos têm configurações similares às situações meteorológicas reais. As demais CP não foram consideradas neste trabalho já que explicam menos de $4 \%$ da variância. Esses padrões também representam situações meteorológicas reais, porém menos frequentes.

Na Fig. 4 observam-se as cinco CP (painéis esquerda) e casos observados (painéis direita) altamente correlacionados com elas.

O primeiro padrão de circulação em superfície (CP1) $(26,4 \%)$ mostra a presença de uma frente fria sobre o leste de SC, que penetra pelo interior do continente em direção ao sudoeste do Paraná (PR), sul e oeste de Mato Grosso do Sul (MS) e leste da Bolívia. O ciclone extratropical associado encontra-se a aproximadamente ao sul do paralelo $40^{\circ} \mathrm{S}$ e próximo ao meridiano $30^{\circ} \mathrm{O}$. Nota-se um anticiclone pós-frontal bastante amplo e intenso, com núcleo sobre o sul da Província de Buenos Aires (leste da Argentina). A crista associada com este sistema anticiclônico se estende de forma meridional em direção ao sul da Bolívia. Outro sistema de baixa pressão pode ser visto no oceano Atlântico, aproximadamente em $45^{\circ} \mathrm{O}, 25^{\circ} \mathrm{S}$. Esses ciclones são bastante frequentes durante o verão e geralmente apresentam pouco contraste de temperatura (Vidal, 2010). Este padrão de circulação em superfície determina um forte gradiente de pressão, provocando a intensificação dos ventos de quadrante sudeste sobre boa parte de SC, incluindo a região do Vale do Itajaí. Desta maneira, a advecção de umidade adquire um papel importante que, junto às irregularidades geográficas da área de estudo, contribuem para tornas as chuvas mais volumosas. A situação meteorológica real altamente correlacionada com esta CP1, correspondente ao dia 8 de maio de 2010, mostra um anticiclone migratório de $1029 \mathrm{hPa}$ centrado no centro-norte da Argentina, aproximadamente em $62^{\circ} \mathrm{O}, 30^{\circ} \mathrm{S}$. Nota-se que a crista relacionada com este sistema de alta pressão se estende meridionalmente em direção ao sul e leste da Bolívia. No Atlântico, aproximadamente em $45^{\circ} \mathrm{O}, 26^{\circ} \mathrm{S}$, observa uma baixa de $1014 \mathrm{hPa}$ que favorece a intensificação da convergência de massa e umidade sobre a área de estudo.

O segundo padrão de circulação em superfície (CP2) $(20,4 \%)$ mostra a presença de uma frente fria no oceano, na altura de SC, cujo anticiclone pós-frontal penetra de forma zonal sobre o oeste e noroeste do Rio Grande do Sul (RS), centro-oeste de SC e o sudoeste do PR. O ciclone frontal associado com esta frente fria, se encontra no oceano Atlântico centrado aproximadamente em $43^{\circ} \mathrm{O}, 40^{\circ} \mathrm{S}$. A situação meteorológica real altamente correlacionada com esta CP2, correspondente ao dia 23 de julho de 2007, mostra um anticiclone migratório de $1017 \mathrm{hPa}$ penetrando sobre a porção oeste da Região Sul do Brasil e a frente fria bem afastada do continente. Esta configuração de pressão em superfície determina um fluxo prevalecente de sul/sudeste 

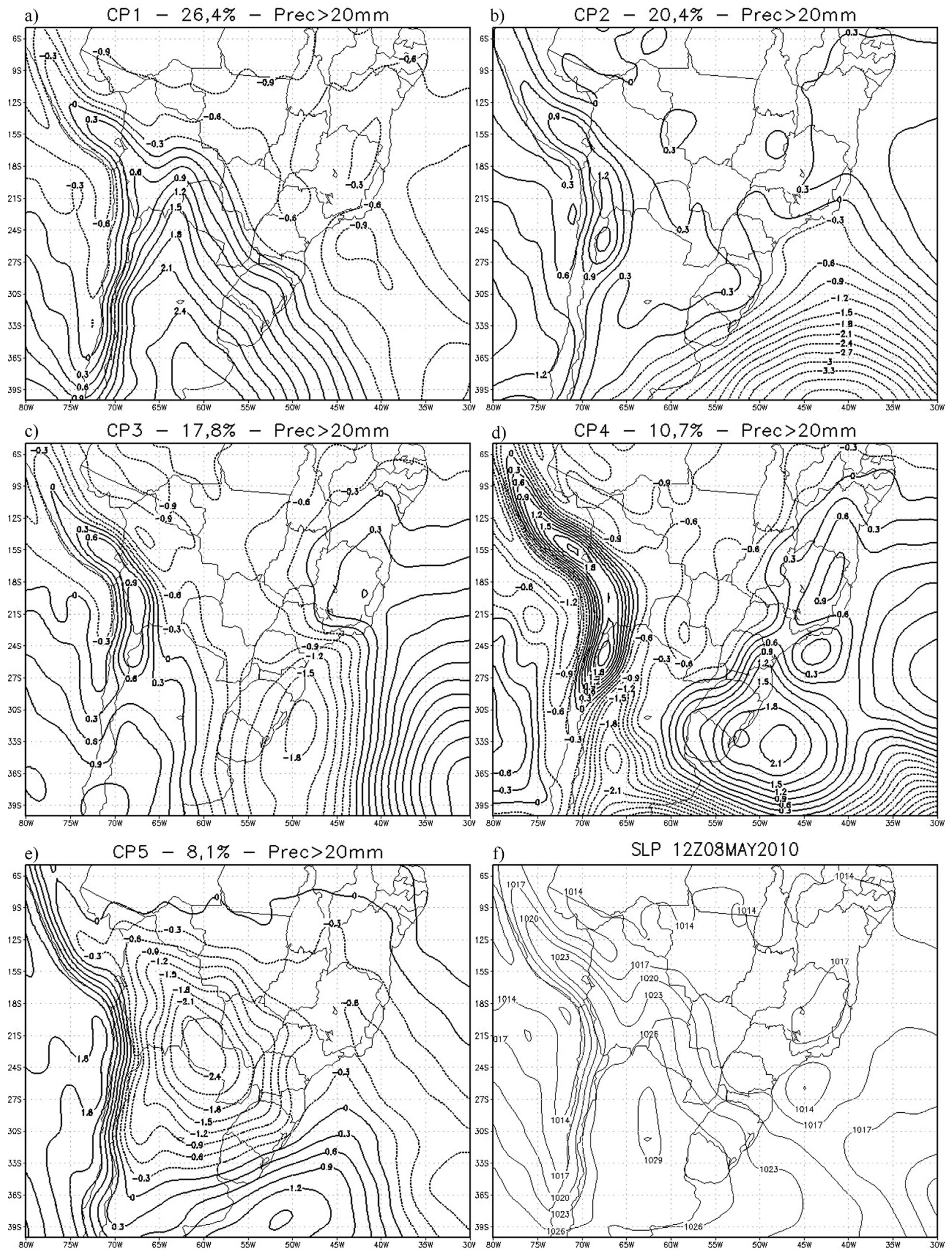

Figura 4 - Componentes principais (esquerda) e situações meteorológicas reais (direita) associadas a frentes frias com precipitação acima de 20 mm na região do Vale do Itajaí. 

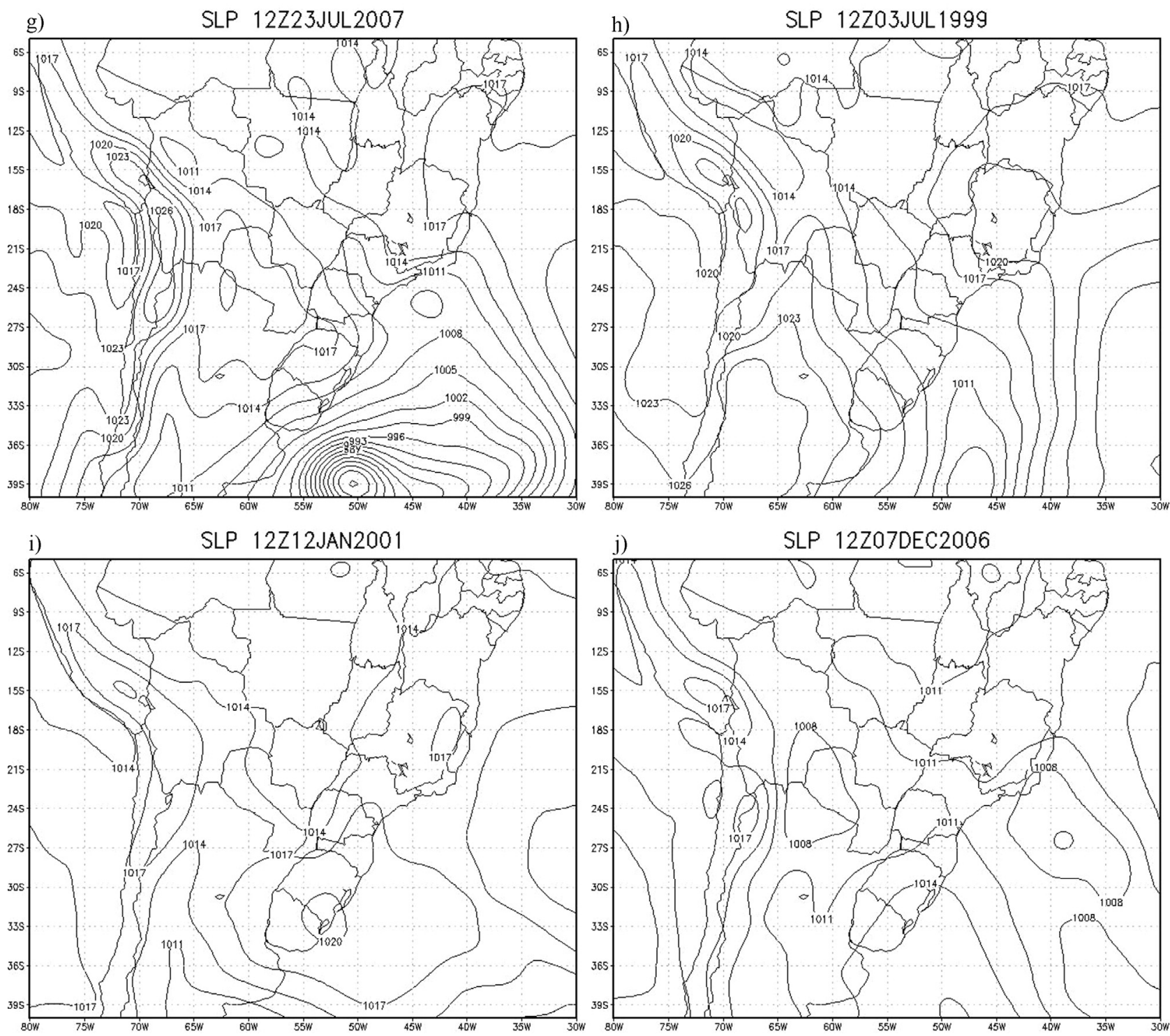

Figura 4 - Cont.

sobre o leste de SC, incluindo a região do Vale do Itajaí. Desta forma, o sistema frontal tende a avançar mais rápido podendo provocar chuva significativa, porém, provavelmente, de mais curta duração.

O terceiro padrão sinótico de superfície (CP3) $(17,8 \%)$ está associada à presença de uma onda frontal posicionada aproximadamente a leste do RS, cujo ramo frio se estende de maneira meridional sobre o leste de SC, do PR e o extremo sul de São Paulo (SP). O anticiclone pós-frontal encontra-se localizado ao sul do paralelo $40^{\circ} \mathrm{S}$ e sua crista associada se estende em direção ao centro-norte da Argentina, sul da Bolívia e o oeste do Paraguai. A localização e características do ciclone sugerem um processo ciclogenético entre o nordeste da Argentina, norte do Uruguai e o RS (Gan e Rao, 1996). A situação meteorológica real altamente correlacionada com esta CP3 (3 de julho de 1999) apresenta a frente fria posicionada entre o nordeste do RS e o sul de SC, estendendo-se pelo interior do continente em direção ao leste do Paraguai. Nota-se que o ciclone extratropical se posiciona em $47^{\circ} \mathrm{S}, 39^{\circ} \mathrm{S}$ com um valor central de $1008 \mathrm{hPa}$. O anticiclone pós-frontal de $1026 \mathrm{hPa}$ se estende através da sua crista até o sul da Bolívia e o oeste do Paraguai.

O quarto padrão sinótico de superfície (CP4) (10,7\%) mostra um intenso anticiclone pós-frontal centrado no oceano Atlântico a sudeste do RS, aproximadamente em $47^{\circ} \mathrm{O}, 34^{\circ} \mathrm{S}$. A frente fria se estende desde o oceano Atlântico $\left(30^{\circ} \mathrm{O}, 40^{\circ} \mathrm{S}\right)$ em direção ao extremo sul de SP, onde se une a um ciclone posicionado em $44^{\circ} \mathrm{O}, 25^{\circ} \mathrm{S}$. Este tipo de situação meteorológica geralmente está relacionado com episódios de Zona de Convergência do Atlântico Sul (ZCAS) sobre o Estado de SP (Escobar e Carvalho, 2005). O ciclone extratropical que se encontra no oceano apresenta características subtropicais devido ao fraco gradiente 
horizontal de temperatura (Vidal, 2010), porém seu ramo frio associado, ou frente fria subtropical, (Sanders, 2005) aumenta a convergência de massa e organiza um canal de umidade desde o Atlântico até o interior das Regiões Sudeste, Centro-Oeste e Norte do Brasil. Por outro lado, o anticiclone pós-frontal aumenta a convergência de massa $\mathrm{e}$ umidade sobre o nordeste de SC, leste do PR e o sul de SP, contribuindo para a intensificação das chuvas sobre estas áreas, incluindo a região do Vale do Itajaí. A situação meteorológica real altamente correlacionada com esta CP4, correspondente ao dia 12 de janeiro de 2001, mostra um anticiclone pós-frontal de $1020 \mathrm{hPa}$ localizado aproximadamente sobre o sudeste do RS, na divisa com o Uruguai. A frente fria se estende ao longo do Atlântico em direção ao extremo sul do Estado paulista e contribui para intensificar os ventos de quadrante leste/sudeste sobre a área de estudo.

Ressalte-se que os episódios de ZCAS persistem por vários dias, podendo estar associados a situações de bloqueio (Seluchi e Chou, 2009). O anticiclone pós-frontal se mantém estacionário fazendo com que as chuvas sejam mais persistentes, devido ao constante fluxo de umidade de quadrante leste. Desta maneira, pode-se inferir que o impacto na população das áreas vulneráveis pode-se tornar ainda maior.

O quinto padrão sinótico de superfície $(\mathrm{CP} 5)(8,1 \%)$ mostra também a atuação do anticiclone pós-frontal influenciando o tempo sobre o leste de SC. A frente fria aparece posicionada sobre o Estado do Rio de Janeiro (RJ) e o núcleo anticiclônico se encontra aproximadamente em $51^{\circ}$ $\mathrm{O}, 39^{\circ} \mathrm{S}$. Esta configuração determina um fluxo de quadrante leste/nordeste sobre a região do Vale do Itajaí, favorecendo a intensificação das chuvas. Esta CP5 também mostra a Baixa do Chaco (BCH) (Escobar e Seluchi, 2012), sistema térmico mais frequente durante a primavera e verão, que contribui para advectar ar quente e úmido da região amazônica sobre grande parte da Região Sul do Brasil, fornecendo um ingrediente fundamental para a geração de chuvas volumosas. $\mathrm{O}$ campo de pressão correspondente ao dia 7 de dezembro de 2006, apresenta uma situação meteorológica altamente correlacionada com esta CP5. Nota-se a presença da $\mathrm{BCH}$, do anticiclone pós-frontal e da frente fria com características semelhantes às descritas nesta CP5.

A Tabela 2 mostra a distribuição da variância explicada pelos cinco primeiros padrões de circulação durante os períodos do inverno (maio - setembro) e verão (outubro abril), respectivamente. Observa-se que todos os padrões sinóticos apresentam maior porcentagem de variância durante o verão, sendo que as $\mathrm{CP} 2, \mathrm{CP} 4$ e CP5 mostram as maiores diferenças entre ambas as estações. Este resultado é coerente já que, especialmente as CP4 e CP5, correspondem a situações típicas de verão e associadas a maiores conteúdos de umidade.

\subsubsection{Frentes frias no leste de SC e oceano adjacente}

Com a finalidade de comparar com os resultados anteriores esta seção realiza uma análise semelhante dos campos de pressão correspondentes a todos os episódios de frentes frias selecionadas no leste de SC e o oceano adjacente. A metodologia identificou sete componentes principais (CP) (Tabela 3) que explicaram $88,4 \%$ da variância total, sendo que as quatros primeiras $\mathrm{CP}$ representaram $75,7 \%$ da variância total e apresentam componentes de peso (ou factor loadings) maiores que 0,7 . As demais $\mathrm{CP}$ não foram consideradas já que explicam menos de $6 \%$ da variância.

Na Fig. 5 observam-se as quatro CP (painéis esquerda) e os casos observados (painéis direita) altamente correlacionados com elas.

O primeiro modelo de circulação em superfície (CP1) $(24,9 \%)$ mostra a presença de uma típica frente fria sobre o leste de SC, cujo ciclone extratropical associado se encontra posicionado ao sul do paralelo $40^{\circ} \mathrm{S}$ e na altura do meridiano $40^{\circ} \mathrm{O}$. É possível observar também um anticiclone pós-frontal ingressando aproximadamente sobre o sul do RS. A situação meteorológica real altamente correlacionada corresponde ao dia 5 de outubro de 1997 e mostra o sistema frontal frio na altura do sul de SC, cujo anticiclone pós-frontal migratório de $1014 \mathrm{hPa}$ se encontra no centro da Argentina. Este modelo de circulação em superfície, que representa a maior porcentagem da variância, é similar ao campo médio achado por Rodrigues et al. (2004).

O segundo modelo de circulação (CP2) $(21,7 \%)$ mostra uma frente fria sobre o extremo sul de SC, quase na divisa com o RS. Nota-se um fluxo predominante de sudes-

Tabela 2 - Porcentagens da variância total explicada e da variância acumulada pelas cinco primeiras CP durante o inverno (maio-setembro) e verão (outubro-abril), associadas a frentes frias com precipitação acima de $20 \mathrm{~mm}$ na região do Vale do Itajaí.

\begin{tabular}{lccccc}
\hline & CP1 & CP2 & CP3 & CP4 & CP5 \\
\hline TOTAL & $26,4 \%$ & $20,4 \%$ & $17,8 \%$ & $10,7 \%$ & $8,1 \%$ \\
MAI-SET & $12,2 \%$ & $7,7 \%$ & $7,6 \%$ & $2,6 \%$ & $2,4 \%$ \\
OUT-ABR & $14,2 \%$ & $12,7 \%$ & $10,2 \%$ & $8,1 \%$ & $5,6 \%$ \\
\hline
\end{tabular}

Tabela 3 - Porcentagens da variância explicada e da variância acumulada pelas sete primeiras $\mathrm{CP}$, associadas a frentes frias no leste de SC.

\begin{tabular}{lcc}
\hline CPs & VAR. (\%) & CUM. VAR (\%) \\
\hline 1 & 24,9 & 24,9 \\
2 & 21,7 & 46,6 \\
3 & 20,4 & 67,0 \\
4 & 8,7 & 75,7 \\
5 & 6,0 & 81,7 \\
6 & 4,2 & 85,9 \\
7 & 2,5 & 88,4 \\
\hline
\end{tabular}



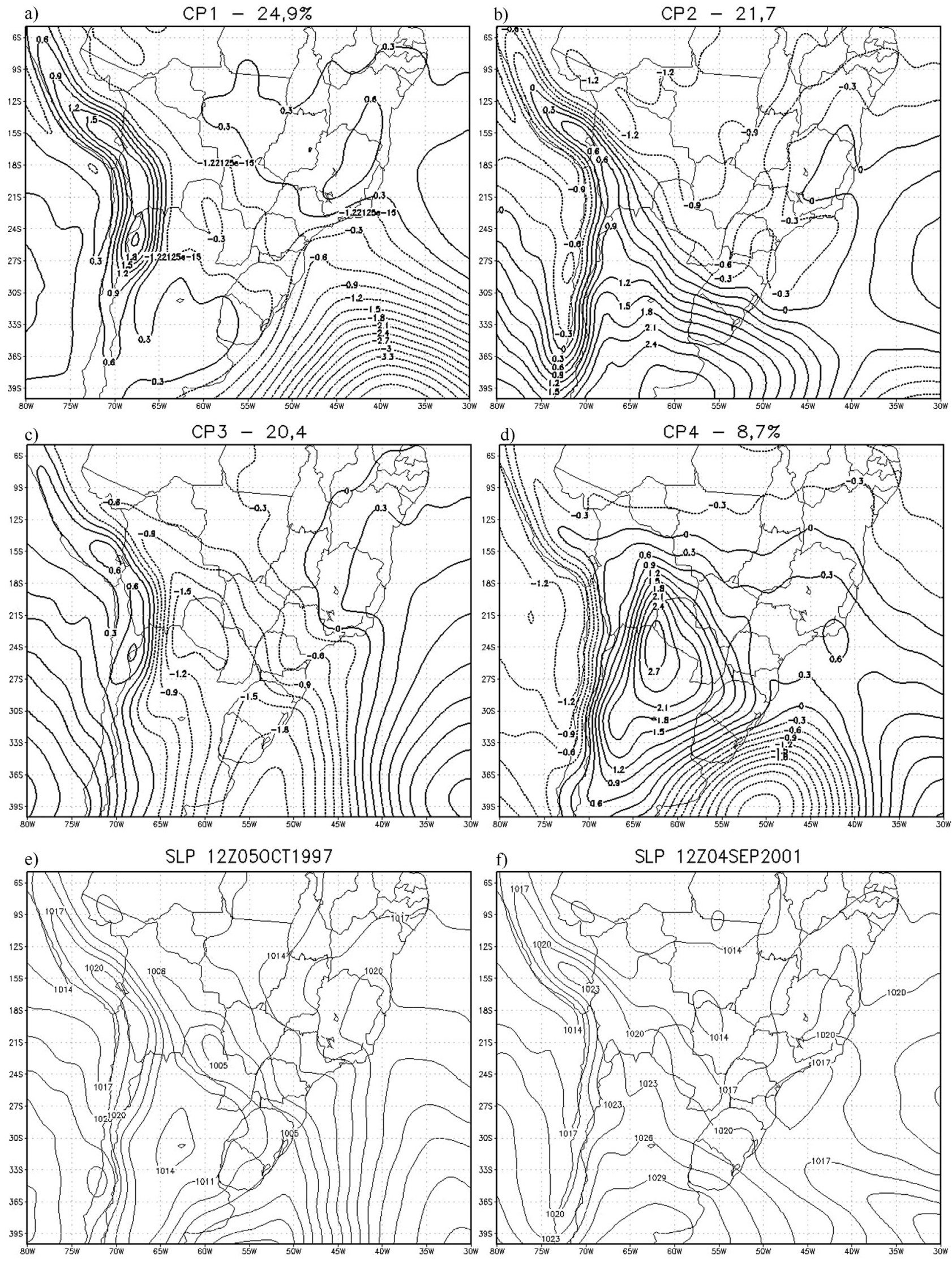

Figura 5 - Componentes principais (esquerda) e situações meteorológicas reais (direita) associadas a frentes frias no leste de SC. 
g)

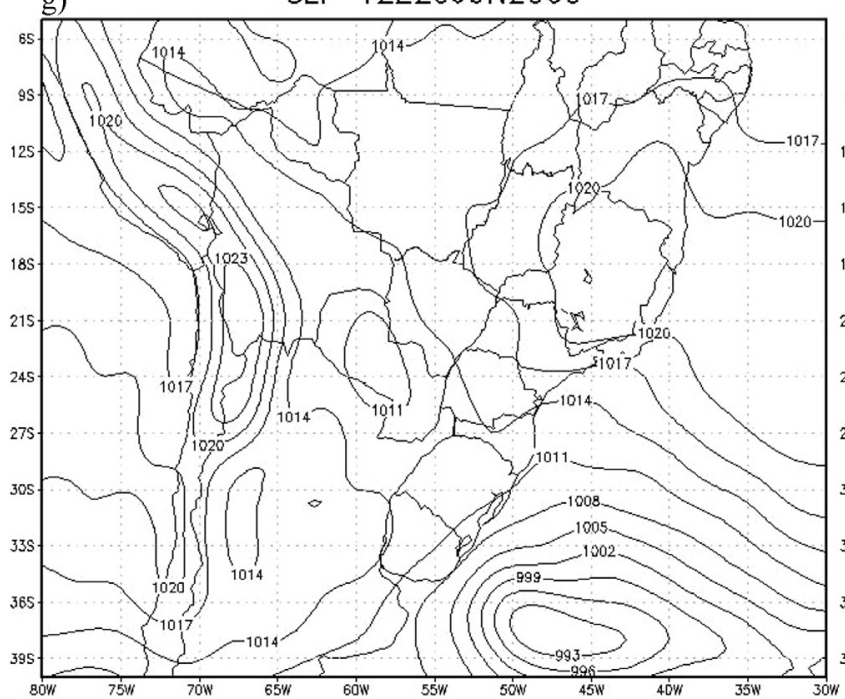

h)

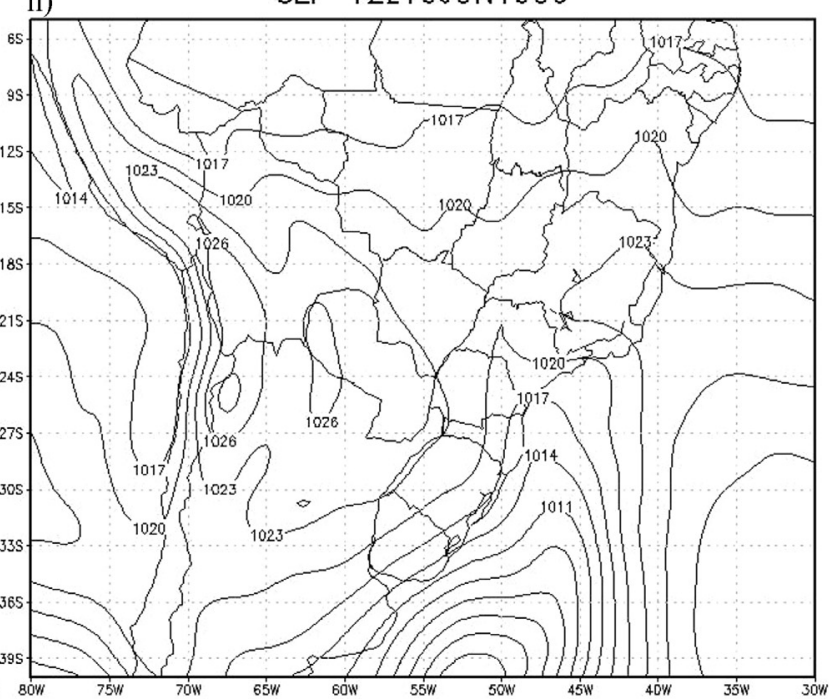

Figura 5 - Cont.

te sobre todo o estado gaúcho e sobre o sul catarinense, devido à presença de um intenso anticiclone pós-frontal centrado aproximadamente em $60^{\circ} \mathrm{O}, 39^{\circ} \mathrm{S}$. Entre o leste $\mathrm{SC}$ e o sul do RJ é possível observar também um cavado invertido, cuja circulação associada favorece a intensificação da convergência de massa e de umidade sobre o leste de SC. A situação meteorológica real altamente correlacionada mostra a frente fria no extremo sul de SC e uma baixa relativa de $1017 \mathrm{hPa}$ no oceano Atlântico entre o leste de $\mathrm{SC}$ e o sul do RJ. No leste da Argentina, aproximadamente em $62^{\circ} \mathrm{O}, 39^{\circ} \mathrm{S}$ observa-se um anticiclone pós-frontal de $1032 \mathrm{hPa}$ que, junto ao sistema de baixa pressão descrito anteriormente, determina um fluxo intenso de sudeste, porém ao sul de SC.

O terceiro modelo de circulação (CP3) (20,4\%) apresenta a frente fria posicionada aproximadamente entre o centro-norte do RS e o extremo sul de SC. Um dos diferenciais deste modelo em relação à $\mathrm{CP} 1$ está relacionado com a presença da Baixa do Noroeste da Argentina (BNOA) (Escobar e Seluchi, 2012), que aparece localizada entre o norte deste pais, centro-oeste do Paraguai e o sul da Bolivia. O significativo gradiente de pressão favorece a intensificação dos ventos de noroeste sobre o norte e leste do Paraguai e boa parte dos estados do PR, MS e SC. Desta maneira, pode-se inferir uma forte advecção de temperatura e umidade proveniente da região amazônica pode favorecer a atividade pré-frontal sobre grande parte dos estados citados anteriormente. A situação real altamente correlacionada com a $\mathrm{CP} 3$, correspondente ao dia 25 de junho do ano 2000, que permite identificar à BNOA com $1012 \mathrm{hPa}$ localizada no centro do Paraguai e uma onda frontal cujo ramo frio se estende em direção ao leste de SC.

O quarto padrão (CP4) (8,7\%) mostra uma frente fria centrada sobre o leste de SC, cujo ciclone extratropical associado localiza-se no oceano aproximadamente em $50^{\circ}$ $\mathrm{O}, 40^{\circ} \mathrm{S}$. Neste caso, observa-se um intenso anticiclone pós-frontal centrado entre o norte da Argentina, sul e oeste do Paraguai e sul da Bolívia, localizado mais ao norte em relação as demais componentes principais analisadas anteriormente. Este modelo de circulação e semelhante às típicas incursões de ar frio sobre o continente sul-americano (Girardi, 1983; Garreaud, 2000; Escobar, 2007). A situãção meteorológica real altamente correlacionada com esta CP4, correspondente ao dia 10 de junho do ano 1999, mostra um anticiclone pós-frontal de $1026 \mathrm{hPa}$ posicionado no extremo norte da Argentina e o oeste do Paraguai. Sobre o Atlântico pode-se observar uma onda frontal, cujo ramo frio se estende quase de forma meridional, sobre o leste de $\mathrm{SC}$, leste do PR e extremo sul de SP. Esta configuração determina um intenso fluxo de quadrante sul/sudoeste sobre o leste de SC, fazendo com que o sistema frontal avance rapidamente.

Com o intuito de identificar a contribuição dos quatro padrões principais de circulação obtidos durante o inverno (maio - setembro) e o verão (outubro - abril), foi calculada a variância explicada por cada um deles durante esses períodos. A Tabela 4 mostra que em termos gerais a CP1 e a CP3 mostram maior porcentagem de variância entre os meses de outubro e abril, enquanto a CP4 apresenta uma maior contribuição durante o inverno (maio - setembro). Durante o verão a BNOA é mais frequente (Escobar e Seluchi, 2012) e adquire maior intensidade quando interage com sistemas frontais vindo de latitudes mais altas. Esta característica poderia contribuir com uma maior frequência de modelos de circulação associados com as CP1 e CP3. Durante o inverno as ondas de frio são mais frequentes, fazendo com que os anticiclones pós-frontais migratórios sejam mais intensos e se desloquem de forma mais meridional atin- 
Tabela 4 - Porcentagens da variância total explicada e da variância acumulada pelas quatro primeiras CP durante o inverno (maio-setembro) e verão (outubro-abril), associadas a frentes frias no leste de SC.

\begin{tabular}{lcccc}
\hline & CP1 & CP2 & CP3 & CP4 \\
\hline TOTAL & $24,9 \%$ & $21,7 \%$ & $20,4 \%$ & $8,7 \%$ \\
MAI-SET & $10,9 \%$ & $10,8 \%$ & $9,4 \%$ & $5,7 \%$ \\
OUT-ABR & $14,0 \%$ & $10,9 \%$ & $11,0 \%$ & $3,1 \%$ \\
\hline
\end{tabular}

gindo latitudes mais baixas. Por essa razão, a CP4 explica maior percentual de variância nessa estação do ano.

\section{Conclusões}

Este estudo tem como objetivo principal identificar os padrões sinóticos associados a passagens de frentes frias causadoras de chuvas extremas na região do Vale do Itajaí. Os sistemas frontais foram selecionados utilizado um método semelhante al elaborado por Andrade (2005), neste caso aplicado às análises do CFSR. Dessa amostra foram separados o $5 \%$ dos casos mais chuvosos (correspondentes a precipitações superiores a $20 \mathrm{~mm} /$ dia) utilizando para isso os campos de precipitação do "MERGE" (Rozante et al. (2010)). A partir dos campos de pressão em superfície foi elaborada uma classificação sinótica utilizando a metodologia de Análise de Componentes Principais rotacionadas em Modo-T. A metodologia foi aplicada separadamente para as frentes que causam chuvas extremas no Vale do Itajaí, no período 1998-2010, e para a totalidade das frentes frias selecionadas sobre o leste de SC, e o oceano adjacente, para o período 1979-2010.

As frentes frias associadas a chuvas extremas no Vale do Itajaí ocorrem com maior frequência durante a primavera e durante o mês de janeiro, diferentemente do que ocorre com a totalidade das frentes frias, que são mais frequentes durante o inverno e o início da primavera. Essa característica sugere que o volume pluviométrico é o resultado não só do padrão dinâmico vinculado aos sistemas, senão também das características termodinâmicas das massas de ar envolvidas. No período de inverno a baroclinia e a frequência de passagens frontais são maiores, porém as condições termodinâmicas não favorecem a ocorrência de chuvas intensas. Durante a primavera e o início do verão a combinação de condições termodinâmicas favoráveis e a frequência ainda relativamente alta de passagens frontais, determinam a ocorrência do maior número de episódios de chuva extrema no Vale do Itajaí.

A Análise de Componentes Principais identificou cinco padrões significativos associados a frentes frias que provocam chuvas superiores a $20 \mathrm{~mm} /$ dia no Vale do Itajaí. Essas cinco primeiras componentes principais (CP) explicaram $83,4 \%$ da variância total. O percentual de variância explicada é maior no verão, o que provavelmente é consequência do maior teor de umidade disponível.

O padrão sinótico mais frequente a essas situações (CP1) $(26,4 \%)$ está associado à atuação de uma frente fria posicionada aproximadamente no leste de $\mathrm{SC}$ e de um intenso anticiclone pós-frontal centrado sobre o leste da $\mathrm{Ar}$ gentina, além de uma área de baixa pressão sobre o oceano, aproximadamente em $42,5^{\circ} \mathrm{O}, 25,5^{\circ} \mathrm{S}$. A combinação destes três sistemas (frente fria, anticiclone e baixa) favorece o aumento do vento de sudeste e, portanto, da convergência de umidade sobre o Vale do Itajaí.

O segundo padrão sinótico $(20,4 \%)$ mostrou a frente fria posicionada aproximadamente sobre o leste de SC, associada a uma baixa frontal relativamente intensa. $\mathrm{O}$ antinciclone pós-frontal é relativamente fraco e se posiciona entre o centro-norte da Argentina e o RS, determinando um fluxo de sul/sudeste sobre a área de estudo que sugere uma maior velocidade de deslocamento do sistema. Este modelo é similar ao encontrado por Rodrigues et al. (2004), quem realizou uma climatologia de frentes frias sobre o litoral de SC. Em consequência, o padrão mais frequente associado à totalidade das frentes (a média aritmética) não representa o padrão mais recorrente associado a chuvas superiores a 20 $\mathrm{mm} /$ dia. Por outro lado, uma pequena, porém provavelmente importante, diferença entre o campo médio correspondente à totalidade das frentes frias e a CP2 é que o fluxo sobre o leste de $\mathrm{SC}$ resulta muito mais intenso neste último caso.

O padrão sinótico correspondente à CP3 (17,8\%) está relacionado à formação de uma onda frontal imediatamente a leste do RS, cujo ramo frontal passa próximo ao Vale do Itajaí. $\mathrm{O}$ anticiclone pós-frontal, de intensidade moderada, se estende meridionalmente desde a Patagônia até o sul da Bolívia. Este tipo de situação está normalmente precedida por forte advecção de ar quente e úmido, o que permite a interação do ramo frio sobre o leste de SC com uma massa de ar instável, favorecendo assim a ocorrência de chuva intensa.

O quarto padrão sinótico (10,7\%) corresponde a uma típica situação de ZCAS sobre o Estado de SP, que inclui a presença de uma baixa localizada sobre o oceano ao sul do RJ e de um anticiclone imediatamente ao sul, posicionado à leste do RS. Ambos os sistemas (baixa e alta) contribuem para a manutenção de um intenso fluxo de umidade de sudeste sobre o Vale do Itajaí.

A CP5 $(8,1 \%)$ está relacionada com o desenvolvimento da $\mathrm{BCH}$, sistema, típico de verão que provoca a intensificação a advecção de ar quente e úmido desde a região amazônica, que resulta máxima sobre o leste de SC.

Considerando a totalidade das frentes frias selecionadas sobre o leste de SC, a metodologia identificou quatro componentes principais (CP) significativas que explicaram $75,7 \%$ da variância total. Como era esperado, o padrão que explica o maior percentual da variância é equivalente ao campo médio obtido por Rodrigues et al. (2004)).

O quarto padrão identificado corresponde a uma típica incursão de ar frio sobre o Centro-Sul do Brasil, que não é compatível com episódios de chuva extrema em SC. Os outros três padrões representativos (CP1, CP2 e CP3) apre- 
sentam certas semelhanças com as obtidas para as frentes frias causadoras de chuvas extremas, porém mostram algumas diferenças sinóticas importantes e um grau de importância diferente.

A análise da variabilidade sazonal de cada um dos quatro padrões sinóticos também mostra um comportamento diferente, já que para as chuvas extremas em SC a variabilidade explicada pelos padrões significativos é maior no verão, enquanto para a totalidade das frentes frias não existe uma diferença clara.

A partir da análise anterior pode se destacar que o padrão sinótico mais frequente para os casos de chuvas extremas no Vale do Itajaí (frente fria seguida de uma alta pós-frontal que provoca ventos intensos de sudeste) não corresponde ao campo médio de todas as frentes frias que passam pela região. Em consequência, esse resultado apresenta um alto valor preditivo, se tornando o "modelo conceitual" mais representativo da ocorrência de chuvas estremas na região de estudo.

$\mathrm{O}$ segundo padrão mais frequente (CP2 na Fig. 4) é relativamente semelhante ao campo mais frequente associado à totalidade das frentes (CP1 na Fig. 5), porém o anticiclone pós-frontal se localiza mais para o norte, permitindo um fluxo mais de sudeste (na CP1 da Fig. 5 o fluxo é mais de sudoeste) sobre o Vale de Itajaí. Novamente, a componente leste do vento parece ser um elemento importante para determinar o valor pluviométrico acumulado. Esse fato pode estar, provavelmente, relacionado à topografia da região do Vale de Itajaí e, obviamente, à sua proximidade com o oceano. $\mathrm{O}$ terceiro padrão, associado à presença de ondas frontais, também apresenta alguma semelhança entre ambas as amostras (CP3 nas Figs. 4 e 5). Contudo, nos casos associados a chuvas extremas o ciclone se localiza mais para o norte e comparativamente muito mais próximo da costa de SC. Os dois padrões restantes estão associados a situações típicas de verão (ZCAS e BCH intensa) apenas significativos para casos de chuvas superiores a $20 \mathrm{~mm} /$ dia.

Em síntese, dos cinco modelos conceituais associados a chuvas extremas no Vale de Itajaí apenas um deles (o segundo em variância explicada) é também representativo do total de frentes frias que passam pela região, correspondente ao campo médio dessas situações, embora com diferenças importantes, como já foi comentado. Os outros modelos restantes correspondem a situações menos frequentes na amostra total de frentes frias, onde a advecção de umidade desde o oceano, ou a presença de um ciclone frontal nas vizinhanças são as características que determinam a ocorrência de volumes pluviométricos mais extremos ( $5 \%$ dos casos mais chuvosos).

Por fim, destaca-se que esse estudo fornece elementos úteis para a elaboração de ferramentas operacionais (semelhança entre os campos previstos por um modelo numérico e os achados neste artigo) com vistas a prever a ocorrência de eventos extremos de chuva no leste de SC. Isso será objeto de trabalhos futuros.

\section{Agradecimentos}

Os autores agradecem o apoio do Conselho Nacional de Desenvolvimento Científico e Tecnológico (CNPq) através da concessão do projeto 473149/2012-5.

\section{Referências}

ANDRADE, K.M. Climatologia e comportamento dos sistemas frontais sobre a América do Sul. 2005. 185 f. Dissertação (Mestrado em Meteorologia) - Instituto Nacional de Pesquisas Espaciais, São José dos Campos, 2005.

CATTELL, R. The scientific use of factor analysis: in Behavioral and Life Sciences. Plenum Press. New York and London, 1978.

CAVALCANTI, I.F.A.; KOUSKY, V.E. Frentes frias sobre o Brasil. Tempo e Clima no Brasil. Oficina de Textos, 2009.

COMPAGNUCCI, R.; SALLES, M.A. Surface Pressure Patterns during the year over Southern South America. International Journal of Climatology , v. 17, n. 6, p. 635-653, 1997.

ESCOBAR, G.C.J.; BISCHOFF, S.A. Meteorological situations associated with significant temperature falls in Buenos Aires: an application to the daily consumption of residential natural gas. Meteorol. Appl., v. 6, n. 3, p. 253-260, 1999.

ESCOBAR, G.C.J.; CARVALHO, C.I. Situações meteorológicas associadas a episódios da Zona de Convergência do Atlântico Sul (ZCAS). In: CONGRESSO ARGENTINO DE METEOROLOGIA, 9, Buenos Aires. Anais Buenos Aires: Editora, 2005.

ESCOBAR, G.C.J. Padrões sinóticos associados a ondas de frio na cidade de São Paulo. Revista Brasileira de Meteorologia, v. 22, p. 241-254, 2007.

ESCOBAR, G.C.J. Jatos de altos níveis. Tempo e Clima no Brasil. Oficina de Textos, 2009.

ESCOBAR, G.C.J.; SELUCHI, M.E. Classificação sinótica dos campos de pressão atmosférica na América do Sul e sua relação com as baixas do Chaco e do Noroeste argentino. Revista Brasileira de Meteorologia, v. 27, p. 365-375, 2012.

ESCOBAR, G.C.J. Padrões de Circulação em Superfície e em 500 hPa na América do Sul e eventos de anomalias positivas de precipitação no estado de Minas Gerais durante o mês de dezembro de 2011. Revista Brasileira de Meteorologia, v. 29, n. 1, p. 105-124, 2014.

FOSS, M.; SELUCHI, M.E.; CHOU,S.C. Análise climatológica da frequência de frentes frias na América do Sul. In: SIMPÓSIO INTERNACIONAL DE CLIMATOLOGIA, 5. (SIC)., Florianópolis, SC. Anais... 2013.

GAN, M.A.; RAO,V.B. Comments on "Climatology of cyclongenesis for the Southern Hemisphere". Mon. Wea. Rev., v. 124, p. 2614-2614, 1996.

GIRARDI, C. O Poço dos Andes. Relatório Técnico ECA 01/83, Centro Técnico Aeroespacial, 1983.

GREEN, P. Analyzing Multivariate Data. The Dryden Press. Illinois, U.S.A, 519, 1978.

GUIA, C.V.F. Análises das características sinóticas das trajetórias dos ciclones extratropicais que atuam na América do Sul e Vizinhanças. 2010. 105 f. Dissertação (Mestrado em Meteorologia) - Instituto Nacional de Pesquisas Espaciais, São José dos Campos, 2010. 
HARMAN, H. Modern Factor Analysis. The University of Chicago Press Chicago, IL, 1976.

HERRMANN, M.L.P.; PELLERIN,J.R.G.M.; SAITO,S.M. Análise das ocorrências de escorregamentos no Estado de Santa Catarina com base nos formulários de Avaliação de Danos da Defesa Civil - 1980 a 2003. In: Simpósio Brasileiro de Desastres Naturais, 1., 2004, Florianópolis. Anais... Florianópolis: GEDN/UFSC, 2004. (CD-ROM).

HOSKINS, B.J.; HODGES, K.I. A new perspective on the southern hemisphere storm tracks. J. Climate, v. 18, p. 4108-4129, 2005.

JUSTI DA SILVA, M.G.A.; SILVA DIAS, M.A.F. A frequência de fenômenos meteorológicos na América do Sul: uma climatologia. Anais do XII Congresso Brasileiro de Meteorologia, Foz do Iguaçu, 2002.

LEMOS, C. F.; CALBETE, N. O. Sistemas Frontais que atuaram no Brasil de 1987 a 1995. Climanálise Especial, Edição comemorativa de 10 anos. MCT/INPE-CPTEC, 1996.

MAY, W. Variability and extremes of daily rainfall during the Indian summer monsoon in the period 1901-1989. Global and Planetary Change, v. 44, p. 83-105, 2004.

MARCELINO, E.V.; GOERL, R.F. Distribuição espaço-temporal de inundações bruscas em Santa Catarina (período 1980-2003). In: Simpósio Brasileiro de Desastres Naturais, 1., 2004, Florianópolis. Anais... Florianópolis: GEDN/UFSC, 2004. (CD-ROM)

OLIVEIRA, A.S. 1986. Interações entre Sistemas Frontais na América do Sul e Convecção na Amazônia. INPE-4008TDL/239.

RICHMAN, M. Rotation of Principal Components. Journal of Climatology, v. 6, n. 3, p. 293-335, 1986.

RICHMAN, M.; ANGEL, J.; GONG, X. Determination of Dimensionality in Eingenanalysis. In: V INTERNATIONAL MEETING ON STATSTICAL CLIMATOLOGY, 6., Canadá. Anais... Canadá. p. 229-235, 1992.

RODRIGUES, M,L.G.; FRANCO, D. ; SUGAHARA, S. Climatologia de frentes frias no litoral de Santa Catarina. Rev. Bras. Geof, v. 22, n. 2, p. 135-151, 2004.
ROZANTE, J.R.; Moreira, D.S.; GONÇALVES., L.G.G.; VILA, D.A. Combining TRMM and Surface Observations of Precipitation: Technique and Validation Over South America. Weather and Forecasting, v. 25, p. 885-894, 2010.

SAHA, S.; MOORTHI, S.; PAN, H.L.; WU, X.; WANG, J.; NADIGA, S.; TRIPP, P.; KIDTLER, R.; WOOLLEN, J.; BEHRINGER, D.; LIU, H.; STOKES, D.; GRUMBINE, R.; GAYNO, G.; WANG, J.; HOU, T.T.; CHUANG, H.Y.; JUANG, H.M.H.; SELA, J.; IREDELL, M.; TREADON, R.; KLEIST, D.; DELST, P.V.; KEYSER, D.; DERBER, J.;EK, M.; MENG, J.; WEI, H.; YANG, R.; LORD, S.; DOOL, H.; KUMAR, A.; WANG, W.; LONG, C.; CHELLIAH, M.; XUE, Y.; HUANG, B.; SCHEMM, J.K.; EBISUZAKI, W.; LIN, R.; XIE, P.; CHEN, M.; ZHOU, S.; HIGGINS, W.; ZOU, C.Z.; LIU, Q.; CHEN, Y.; HAN, Y.; CUCURULL, L.; REYNOLDS, R. W.; RUTLEDGE, G.; GOLDBERG, M. The NCEP Climate Forecast System Reanalysis. Bulletin of the American Meteorological Society, v. 91, n. 8, p. 1015-1057, 2010.

SANDERS, F. Real Front or Baroclinic Trough? Wea. Forecasting, v. 20, p. 647-651, 2005.

SELUCHI, M.E.; CHOU, S.CH, Synoptic patterns associated with landslide events in the Serra do Mar, Brazil. Theoretical and Applied Climatology, v. 98, p. 67-77, 2009.

SELUCHI, M.E.; GARREAUD R.D. Campos médios e processos físicos associados ao ciclo de vida da Baixa do Chaco, Revista Brasileira de Meteorologia, v. 27, n. 4, p. 447-462, 2012.

SEVERO, D.L. Estudo de Casos de Chuvas Intensas no Estado de Santa Catarina. 1994. 97 f. Dissertação (Mestrado em Meteorologia) - Instituto Nacional de Pesquisas Espaciais, São José dos Campos, 1994.

TEIXEIRA, M.S.; SATYAMURTY, P. Dynamical and synoptic characteristics of heavy rainfall episodes in southern Brazil. Monthly Weather Review, v. 135, p. 598-617, 2007.

All the contents of this journal, except where otherwise noted, is licensed under a Creative Commons Attribution License CC-BY. 